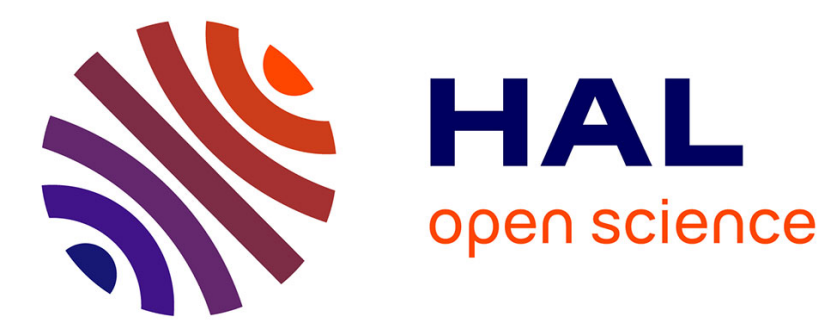

\title{
Glass transition phenomena in D-xylose aqueous solutions: A broadband dielectric spectroscopy study \\ Lokendra Singh
}

\section{To cite this version:}

Lokendra Singh. Glass transition phenomena in D-xylose aqueous solutions: A broadband dielectric spectroscopy study. DAE Solid State Physics Symposium 2015, Dec 2015, Uttar Pradesh, India. pp.070004, 10.1063/1.4947836 . hal-02316579

\section{HAL Id: hal-02316579 \\ https://univ-lyon1.hal.science/hal-02316579}

Submitted on 12 Mar 2020

HAL is a multi-disciplinary open access archive for the deposit and dissemination of scientific research documents, whether they are published or not. The documents may come from teaching and research institutions in France or abroad, or from public or private research centers.
L'archive ouverte pluridisciplinaire HAL, est destinée au dépôt et à la diffusion de documents scientifiques de niveau recherche, publiés ou non, émanant des établissements d'enseignement et de recherche français ou étrangers, des laboratoires publics ou privés. 


\title{
Glass Transition Phenomena in D-xylose Aqueous Solutions: A Broadband Dielectric Spectroscopy Study
}

\author{
Lokendra P. Singh* \\ *Institut Lumiére Matiére,Université Claude Bernard Lyon 1, 69622 Villeurbanne Cedex, France \\ Email: lokendra.singh@univ-lyon1.fr;.lps.jnu@gmail.com
}

\begin{abstract}
Broadband dielectric measurements for D-xylose-water mixture with $\mathrm{x}_{\mathrm{w}}=0.30 \& 0.40$, were performed in the frequency range of $10 \mathrm{mHz}$ to $10 \mathrm{MHz}$ and in the temperature range of $150 \mathrm{~K}$ to $260 \mathrm{~K}$. Differential scanning calorimeter was also carried out to see the thermal behavior of this aqueous solutions. Two relaxation processes were observed, in addition to the contribution of dc conductivity in the low frequency side. The lower frequency process, the so-called primary relaxation process (process-I), is responsible for the glass transition $\left(\mathrm{T}_{\mathrm{g}}\right)$ whereas the faster one or high frequency process (designated as process-II) is due to the reorientational motion of the water molecules.
\end{abstract}

Keywords: Glass transition, Aqueous solutions, D-xylose, Dielectric spectroscopy.

PACS: $64.70 . \mathrm{Pf}$, 77.22.Gm, 78.30.Cp

\section{INTRODUCTION}

With two thirds of the earth's surface covered with water and the human body consisting of $75 \%$ of it, it is evidently clear that water is one of the prime elements responsible for life on Earth. At room temperature, bulk water shows a pronounced loss process at around $19.2 \mathrm{GHz}$ at $293 \mathrm{~K}$ due to the reorientation of water dipoles [1]. In solutions, this process becomes broader and its relaxation times slower, likely because of the intermolecular interaction with the glassy systems. The study of water mixtures becomes very attractive mainly due to the fact that it is possible to address both the dielectric processes of the glass formers in an aqueous environment as well as the dielectric relaxation processes of water at low temperatures that would correspond to supercooled water. Since the water molecule has a big dipolar moment, dielectric spectroscopy is a very adequate technique to analyze the reorientational dynamical behavior of water on a broad frequency range. Thus, a lot of attention has been made in the literature to the dielectric behavior of water dynamics in several aqueous mixtures [2-4].

Here, we performed broadband dielectric measurements on D-xylose water mixture, in order to clarify the molecular dynamics relating to the glass transition and the contribution of non-crystallized water to the relaxation process for the larger solute water mixtures. Differential Scanning Calorimetry was also employed to support the data analysis in order to see the thermal behavior of aqueous solutions.

\section{EXPERIMENTAL}

D-xylose was purchased from Sigma Aldrich (purity $\geq 99 \%$ ) and used as received. In order to prepare aqueous solutions, ultra-pure water having resistivity $\approx 18.2 \mathrm{M} \Omega . \mathrm{cm}$ at $298 \mathrm{~K}$ was used.

Dielectric spectra were obtained by using concept 40 Novocontrol broadband Alpha-analyzer with Novocontrol Quatro Cryosystem (Montabaur, Germany) equipped with two-electrode scheme. The solutions were placed between parallel gold-plated electrodes with a diameter of $30 \mathrm{~mm}$ and a Teflon spacers of $0.1 \mathrm{~mm}$ were used to define the thickness. After cooling at a rate of $10 \mathrm{~K} / \mathrm{min}$, isothermal frequency scans recording $\varepsilon^{*}(\omega)$ were performed every $5 \mathrm{~K}$ over the temperature range of $150-250 \mathrm{~K}$. The sample temperature was controlled with stability better than $\pm 0.1 \mathrm{~K}$.

DSC measurements were performed using Perkin Elmer DSC7, with both cooling and heating rates set to $10 \mathrm{~K} / \mathrm{min}$. The weights of the samples were taken to about $8.5 \mathrm{mg}$. In order to see the thermal behavior of aqueous solutions, first the liquid samples were cooled at a rate of $10 \mathrm{~K} / \mathrm{min}$ to the lowest temperature, i.e., 130 K. Subsequently, the data were collected by heating the sample at a rate of $10 \mathrm{~K} / \mathrm{min}$ from 130 to 
$270 \mathrm{~K}$. The temperature calibration of the DSC instrument was done at the rates of $\pm 10 \mathrm{~K} / \mathrm{min}$ using Indium as standard.

\section{RESULTS AND DISCUSSION}

Before starting the dielectric measurements, first DSC measurements were performed, in order to obtain the calorimetric glass transition temperatures $\left(\mathrm{T}_{\mathrm{g}}\right)$ as a function of water concentration. The maximum water concentration in D-xylose-water mixtures was kept under $\mathrm{x}_{\mathrm{w}}=0.40$, to avoid crystallization of the sample during cooling. A representative DSC curve showing the heat flow of D-xylose-water mixture with $\mathrm{x}_{\mathrm{W}}=$ 0.40 during cooling and heating (at a rate of $10 \mathrm{~K} / \mathrm{min}$ ) is shown in Figure 1. The DSC curve is shown in Figure 1 clearly identifies that crystallization can be avoided during cooling to obtain a glassy phase at low temperatures. However, the heating curve depicted in Figure 1 shows a glass transition $\left(\mathrm{T}_{\mathrm{g}}\right)$ followed by cold crystallization in the temperature range $210-230 \mathrm{~K}$. After that a broad melting peak is observed in the temperature range in between $240-260 \mathrm{~K}$. The $\mathrm{T}_{\mathrm{g}}$ 's of all the samples were estimated as the onset of the heat flow step.

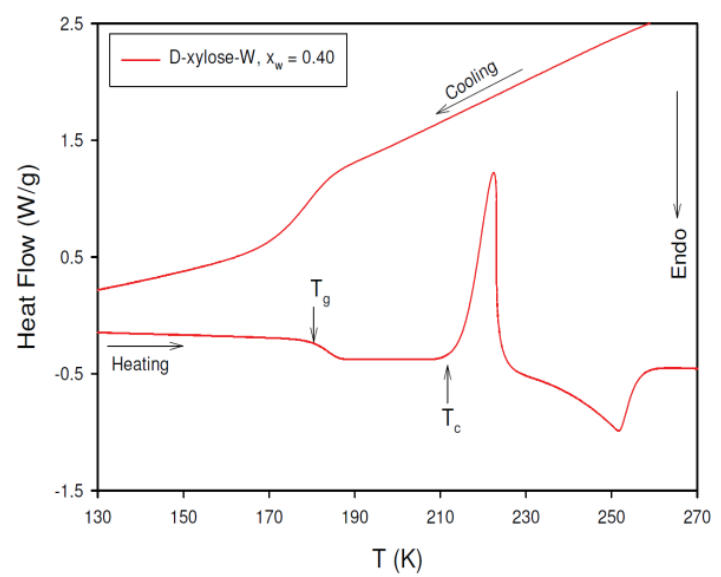

FIGURE 1. Representative example of the temperature dependence of heat flow measured by DSC during cooling as well as heating at a rate of $10 \mathrm{~K} / \mathrm{min}$ of $\mathrm{D}$-xylose aqueous solution with $\mathrm{x}_{\mathrm{w}}=0.40$. (Here, $\mathrm{x}_{\mathrm{W}}=$ weight fraction of water)

After accessing calorimetric results, dielectric measurements have been carried out on D-xylose aqueous solutions. The typical dielectric loss spectra for D-xylose-water $\left(x_{\mathrm{w}}=0.30\right)$ is drawn in Figure 2 at various temperatures. This figure clearly identifies that the qualitative behavior of this aqueous mixture is quite similar to many other glass formers. Two relaxa-
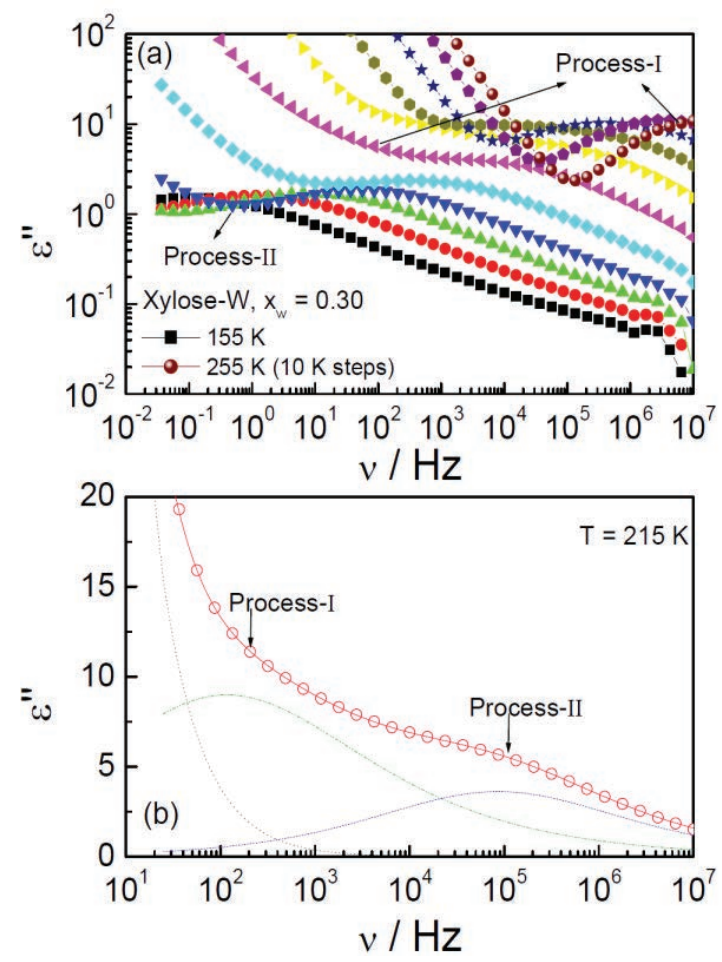

FIGURE 2. D-xylose-Water system, $x_{w}=0.30$ : (a) frequency dependent dielectric loss spectra at various temperatures. (b) Frequency dependence of dielectric loss curve at a fixed temperature $\mathrm{T}=215 \mathrm{~K}$. The solid line in panel $b$ is least squares fit using eq. 1 . The dashed double dotted line along process-I, dashed line along process-II and dotted line represents the imaginary part of $\mathrm{HN}, \mathrm{CC}$ and conductivity fits respectively.

-tion processes were observed in this binary system (called process-I and process-II). However, both processes are highly influenced by the addition of water molecules. All dielectric spectra were analyzed by following well known Havriliak-Negami (HN) function [5] of the form given by,

$$
\varepsilon^{*}(\omega)=\varepsilon^{\prime}(\omega)-i \varepsilon^{\prime \prime}(\omega)=\varepsilon_{\infty}+\sum_{j} \frac{\Delta \varepsilon_{j}}{1+\left(i \omega \tau_{j}\right)^{\alpha_{j} Y^{\gamma_{j}}}}+\frac{\sigma_{0}}{i \omega \varepsilon_{0}}
$$

Here, $\Delta \varepsilon_{\mathrm{j}}=\varepsilon_{\mathrm{sj}}-\varepsilon_{\infty \mathrm{j}}$ is the dielectric strength of the $\mathrm{j}^{\text {th }}$ process, $\tau_{\mathrm{j}}$ is the $\mathrm{HN}$ - relaxation time, $\alpha_{\mathrm{j}}$ and $\gamma_{\mathrm{j}}$ represent the symmetric and asymmetric broadening of the loss curve $(0<\alpha, \alpha \gamma \leq 1)$, and $\varepsilon_{\infty}$ is the high frequency limit of the real part of the permittivity. In the present case, an $\mathrm{HN}$-function was used to fit primary relaxation process or process-I and a ColeCole function (obtained by setting $\gamma=1$ in above HN expression) to fit secondary relaxation or process-II. 

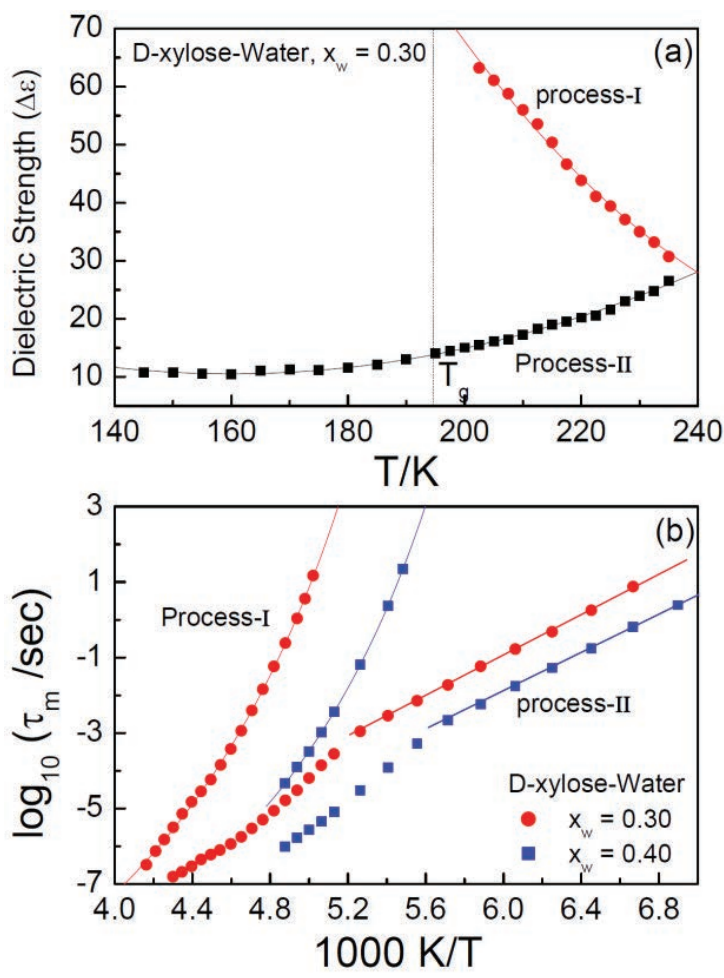

FIGURE 3. (a) Temperature variation of dielectric strengths of process-I and II of D-xylose aqueous solution with $\mathrm{x}_{\mathrm{w}}=$ 0.30 (b) Complete Arrhenius plot of D-xylose aqueous solutions with $\mathrm{x}_{\mathrm{w}}=0.30,0.40$. The solid lines along process$\mathrm{I}$ are VFT fits and along process-II are fits to the Arrhenius equation obtained by putting $\mathrm{T}_{0}=0$ in VFT eq. (2).

Representative fit results for this binary system at a fixed temperature are shown in Figure 2(b). From this figure, it is clear that the nature of the low frequency process (process-I) is similar to those observed in pure glass formers as well as hydrated samples [2-4,6,7]. This indicates that it is due to the cooperative motion of homogeneous mixture which is plasticized and becomes faster in the presence of water. In addition to above said relaxation process, a new relaxation process, named as process-II is observed in the hydrated samples. In Figure 3(a), the corresponding variation of dielectric strength with temperature is plotted. The important feature of this figure is a noticeable increase in the dielectric strength of process-II above $\mathrm{T}_{\mathrm{g}}$. With increasing water concentration, process-II becomes more dominant and because of this reason process-I becomes weak at high water concentration. This suggests that water molecules which are very close to D-xylose are tightly bound to the D-xylose molecules, whereas the water molecules that are far from the D-xylose molecules, called loosely bound water molecules will continue to enjoy reorientational freedom even below $T_{g}$, which is identified as process-II. Similar conclusions were also drowned by various researchers in different aqueous solutions [2-4].

Complete Arrhenius plots are shown in Figure 3(b). The T-dependence of the relaxation times corresponding to process-I, is found to follow the VFT equation given by [8],

$$
\log _{10}[\tau(T) / s]=A+\frac{B}{T-T_{0}}
$$

Where $T_{0}$ is the temperature at which the dynamics of the system diverges, $A$ is a logarithmic pre-exponential factor and $B$ is a constant. The relaxation times corresponding to process-II below $\mathrm{T}_{\mathrm{g}}$ are analyzed by using the Arrhenius equation obtained by putting $\mathrm{T}_{0}=$ 0 in eq. 2. Interestingly the kinetic freezing temperatures of process-I $\left(\mathrm{T}_{\mathrm{g}, 100 \mathrm{~s}}\right)$ are very close to glass transition temperatures obtained from DSC (compare Figure 1 and Figure $3 b$ ). Therefore we concluded that process-I is linked to the glass transition of the D-xylose-water system. Figure 3(b) clearly indicates that D-xylose-water solutions show two-relaxation processes, the lower frequency one (process-I) which is arrested at glass transition temperature $\left(\mathrm{T}_{\mathrm{g}}\right)$ discussed above, whereas the high frequency process designated as process-II show Arrhenius type temperature dependence below $\mathrm{T}_{\mathrm{g}}$. Similar behavior was also observed in several other aqueous solutions [2-4]. These similar properties suggest that process-II in D-xylose aqueous solutions is due the reorientational motion of water molecules in these mixtures.

\section{ACKNOWLEDGMENTS}

Author wishes to thank Prof. B. Issenmann for his kind support and post doc fellowship at University of Claude Bernard Lyon 1, Villeurbanne, France.

\section{REFERENCES}

1. R. Buchner, J. Barthel and J. Stauber, Chem. Phys. Lett. 306, 57-63 (199).

2. N. Shinyashiki, W. Yamamoto, A. Yokoyama, T. Yoshinari, S. Yagihara, R. Kita, K. L. Ngai and S. Capaccioli, J. Phys. Chem. B 113, 14448-14456 (2009).

3. L. P. Singh, S. Cerveny, A. Alegria and J. Colmenero, J. Phys. Chem. B 115, 13817-13827 (2011).

4. L. P. Singh, S. Cerveny, A. Alegria and J. Colmenero, Chem. Phys. Chem. 12, 3624-3633 (2011).

5. S. Havriliak and S. Negami, J. Polym. Sci. part C 14, 99117 (1966).

6. L. P. Singh, A. Alegria and J. Colmenero, Carbohydr. Res. 346, 2165-2172 (2011).

7. L. P. Singh, Int. J. Sci. \& Eng. Res. 6, 533-537 (2015).

8. J. Wong and C. A. Angell, Glass structure: by spectroscopy, Marcel Dekker, New York (1976). 